\title{
Antimicrobial Susceptibility Pattern of Bacteria Isolated from Blood Urine and Wound Swab in Febrile Neutropenic Children in a Tertiary Level Hospital, Bangladesh.
}

\author{
Farook Ahamed', Sazzad Bin Shahid², Shahin Ara Begum², Mohammad Jobayer ${ }^{3}$, Mizanur Rahman² \\ Sultana Shazeda Nahar ${ }^{2}$, Afiqul Islam ${ }^{4}$
}

${ }^{1}$ Directorate General of Health Services (DGHS), Dhaka, 2Department of Microbiology, Dhaka Medical College, Dhaka, ${ }^{3}$ National Center for Control of Rheumatic Fever \& Heart Disease, Dhaka, ${ }^{4}$ Department of Paediatric Hematology and Oncology, Bangabandhu Sheikh Mujib Medical University, Dhaka.

\begin{abstract}
Fever is the commonest symptom of infection in neutropenic children with malignancy, under chemotherapy. To avoid bacterial complications, it is necessary to diagnose infection early and to administer empirical antibiotic. The aim of this study was to find out the causative bacteria and their antimicrobial susceptibility pattern in febrile neutropenic children who were under chemotherapy. The study was conductedin a tertiarylevel hospital,Bangabandhu Sheikh Mujib Medical University (BSMMU), Dhaka, Bangladesh. Blood, urine and wound swab were collected for culture from 30 febrile neutropenic children, age 1-15 years. Out of 70 samples total 26(37.14\%)yielded growth of bacteria among which 6(20\%), 12(40\%), and $8(80 \%)$ were isolated from blood, urine and wound swab respectively. Among thebacteria Pseudomonas spp, Esche coli and Staph aureus weremost frequently isolated. Meropenem, imipenem and netilmicin were the most sensitive against gram negative bacteria and the entire isolated gram positive bacteria were $100 \%$ sensitive to vancomycin and linezolid.
\end{abstract}

Key words: Antimicrobial susceptibility, bacteria, blood, neutropenic children.

\section{Introduction}

Cancer patients, especially those with haematological and lymphoid malignancies, in whom infectious complications represent an important cause of morbidity and mortality, as chemotherapy results in neutropenia in a vast majority of patients. ${ }^{1}$ Bacterial infections are common and potentially serious complications of cancer treatment. ${ }^{2}$ However, this has been obtained with aggressive use of chemotherapy and more use of invasive procedures, which may also contribute to increased susceptibility to infections. ${ }^{3}$ In addition, disruptions of the physicaldefense barriers of skin and mucosa, secondary to chemotherapy, leads to increased exposure to potentially pathogenic micro-organisms.In situ venous access catheters are further risk factors forbacteremia. ${ }^{2}$

Over the past decade there has been a considerable change in the pattern of pathogens causing infections in cancer patients. ${ }^{1}$ A low nadir in the neutrophil count

\section{Correspondence:}

\section{Dr. Farook Ahamed}

Deputy Program Manager (Medical Waste Management) Directorate General of Health Services (DGHS), Dhaka

Mobile: 01715-005842, Email: dr.farook25@gmail.com and protracted neutropenia (i.e.neutrophil count of $<500$ cells/cmm for 10 days) are major risk factors for impending infection. In addition to quantitative changes in neutrophil counts, abnormalities of phagocytic function or other deficits in the immune response may further increase the risk for infection in a neutropenic host. ${ }^{4}$ Among the neutropenic children withfebrile, Staphylococci (both coagulase-negative and coagulase-positive) and Escherichia coli are the most frequently isolated gram-positive and gram-negative organisms respectively.., 6

Beta-lactam and/or aminoglycoside combination for febrile neutropenia is considered better approach, because of its broader spectrum, potential synergistic activity against gram-negative rods, and its potential ability to reduce the emergence of resistant strains. ${ }^{4,6}$ With time the resistance to beta-lactam antibiotics has been on the rise and warrants close monitoring of the sensitivity patterns of different organism regularly. ${ }^{5}$

Though the exact statistics of incidence and prevalence of febrile neutropenia among the patients with cancer in our country is not available but it is the common opinion that the number of such kind of problem is increasing day by day. The aim of this study was to determine the microbiological spectrum by culture of different clinical 
samples during episodes of fever and neutropenia in children with cancer.

\section{Methodology and Method}

This prospective cross sectional studywas conducted in the Department of Paediatric Haematology and Oncology of Bangabandhu Sheikh Mujib Medical University (BSMMU), Dhaka, Bangladesh for a period of 6 months (March-September, 2010). All microbiological works were done in the Department of Microbiology and Immunology, BSMMU.

Study population: Thirtychildren between the age of 1 to 15 years with marrow/biopsy evidence of malignancy and undergoing chemotherapy with clinical features of febrile neutropenia in the Department of Paediatric Haematology and Oncology, BSMMU were included.

Data collection tool: Structured questionnaire and a check list.

Data collection technique: The diagnosis of febrile neutropenia (FN) was made as absolute neutrophil count (ANC) $\leq 500$ cells/cmmwith single oral temperature of $\geq$ $38.3^{\circ} \mathrm{C}$ or a temperature of $\geq 38.0^{\circ} \mathrm{C}$ for $\geq 1$ hour. $^{7}$ All participants were subjected to be thorough clinical examination and tests for hemoglobin, complete blood cell count, peripheral blood film.

Sample collection for culture: Blood, urine, and wound swab were collected for culture under all aseptic precautions and according to standardWHOguideline. ${ }^{8}$ Trypticase soy broth was used for primary culture of blood. Blood agar, MacConkey agarand Chocolate agar media were used for subculture of blood. Urine and wound swab were inoculated in blood agar and MacConkey agar media. All inoculated media were incubated at $37^{\circ} \mathrm{C}$ aerobically over night. In culture positive cases, bacterial identificationwas done by colony morphology, gram staining anddifferentbiochemical tests as per standard guide line. ${ }^{9}$

Antimicrobial susceptibility testing: Antibiotic susceptibility pattern were determined by Kirby-Bauer disc diffusion method ${ }^{10}$ using commercially available antibiotics discs (Oxoid,UK). The organisms were tested against routinely used antibiotics like amikacin, gentamycin, imipenem, meropenem, ceftazidime, ceftriaxone,co-trimoxazole, netilmicin. Zone of inhibition was recorded as sensitive or resistant according to CLSI guideline. ${ }^{11}$

\section{Result:}

Out of total 70 samples $26(37.1 \%)$ yielded growth of bacteria and among them 6(20\%) were blood, 12(40\%) were urine and $8(80 \%)$ were wound swab (Table-I).
Of the six bacteria isolated from blood,2(33.3\%) each were Pseudomonassppand Staph aureus. Among the 12 bacteria isolated from urine samples Esch.coli were 6 (50\%)and Pseudomonasspp. were the maximum number 4 (50\%) isolated from wound swab culture (Table-II).

Among the 26 culture positive cases 10 (38.4\%) had ANC count more than 100 cells/cmm and $16(61.6 \%)$ had ANC count less than 100 cells/cmm (Table-III).

Most of the gram negative bacteria were sensitive to meropenem, imipenem and netilmicin and Staphaureus, B hemolytic Streptococci and Enterococcus sppwere 100\% sensitive to vancomycin and linezolid (Table-IV).

Table-I: Distribution of blood,urine\& wound swabculture of the patients $(\mathrm{N}=70)$

\begin{tabular}{lcc}
\hline Specimen & Positive $\mathrm{n}(\%)$ & Negative $\mathrm{n}(\%)$ \\
\hline Blood $(\mathrm{N}=30)$ & $6(20)$ & $24(80)$ \\
Urine $(\mathrm{N}=30)$ & $12(40)$ & $18(60)$ \\
Wound swab(N=10) & $8(80)$ & $2(20)$ \\
\hline Total $(\mathrm{N}=70)$ & $26(37.1)$ & $54(62.9)$ \\
\hline
\end{tabular}

$\mathrm{N}=$ Total number of samples. $\mathrm{n}=$ positive samples

Table-II: Distribution of organisms isolated from blood, urineand wound swab.

\begin{tabular}{|c|c|c|c|c|}
\hline Organisms & blood n (\%) & u rine $\mathrm{n}(\%)$ & $\begin{array}{ll}\text { wound swab } & \mathrm{n}(\%)\end{array}$ & total n $(\%)$ \\
\hline Pseudomonas spp & $2(33.3)$ & $2(16.7)$ & $4(50)$ & $8(16.7)$ \\
\hline Esch. coli & $1(16.7)$ & $6(50)$ & $0(0)$ & $7(16.7)$ \\
\hline Klebsiella spp & $0(0)$ & $2(16.7)$ & $0(0)$ & $2(16.7)$ \\
\hline Acinetobacter spp & $1(16.7)$ & $0(0)$ & $0(0)$ & $1(16.7)$ \\
\hline Staph aureus & $2(33.3)$ & $0(0)$ & $3(37.5)$ & $5(16.7)$ \\
\hline Enterococcus spp & $0(0)$ & $2(16.7)$ & $0(0)$ & $2(16.7)$ \\
\hline$\beta$ hemolytic Streptococci & $0(0)$ & $0(0)$ & $1(12.5)$ & $1(0)$ \\
\hline Total & $6(100)$ & $12(100)$ & $8(100)$ & $26(100)$ \\
\hline
\end{tabular}

Table-III: Absolute neutrophil count (ANC) among culture positive patients $(n=26)$

\begin{tabular}{ll}
\hline ANC & Number (\%) \\
\hline$>100$ cells/cmm & $10(38.4)$ \\
$<100 \mathrm{cells} / \mathrm{cmm}$ & $16(61.6)$ \\
\hline Total & $26(100)$
\end{tabular}

Table-IV: Antimicrobial sensitivity pattern of isolated bacteria from blood, urine and wound swab.

\begin{tabular}{lccccccccccc}
\hline Isolated organism & \multicolumn{1}{c}{ Sensitive (\%) } \\
& $\mathrm{Ak}$ & $\mathrm{Cro}$ & $\mathrm{Caz}$ & $\mathrm{G}$ & $\mathrm{Cip}$ & $\mathrm{Mem}$ & $\mathrm{Ipm}$ & $\mathrm{Net}$ & $\mathrm{Cot}$ & $\mathrm{Va}$ & Lzd \\
\hline Pseudomonas & 75 & 25 & 75 & 50 & 50 & 87.5 & 100 & 87.5 & 25 & - & - \\
Esch coli & 71.4 & 71.4 & 57.1 & 71.4 & 42.9 & 100 & 100 & 71.4 & 57.1 & - & - \\
Klebsiella spp & 50 & 100 & 0 & 50 & 0 & 100 & 100 & 100 & 50 & - & - \\
Acinetobacter & 100 & 0 & 0 & 0 & 0 & 0 & 0 & 100 & 100 & - & - \\
Staph aureus & 80 & 60 & 60 & 60 & 40 & - & - & - & 80 & 100 & 100 \\
Enterococcus spp & 50 & - & - & 0 & 100 & 100 & 100 & - & 50 & 100 & 100 \\
B hemolytic & 100 & 100 & 0 & 100 & 0 & - & - & - & 100 & 100 & 100 \\
Streptococci & & & & & & & & & & & \\
\hline
\end{tabular}


AK-amikacin, Cro-ceftriaxone, Caz-ceftazidime, G-gentamicin, Cip-ciprofloxacin, Mem-meropenem, Ipm-imipenem, Net-netilmicin, Cot-cotrimoxazole, Va-vancomycin, Lzd-linezolid.

\section{Discussion:}

Febrile neutropenia $(\mathrm{FN})$ is a frequent and potentially life-threatening complication in children with cancer under chemotherapy. ${ }^{7}$ In addition to quantitative changes in neutrophil counts, abnormalities of phagocytic function or other deficits in the immune response may further increase the risk for infection in a neutropenic host. ${ }^{4}$ Fever during chemotherapy-induced neutropenia can be the first sign of bacterial infection and therefore, requires prompt and careful attention. Children with cancer can be severely immune compromised and most chemotherapeutic agents also inhibit the inflammatory response to invading microbes. ${ }^{12}$ Bacterial infectionis common and potentially serious complication of cancer treatment. The etiology, clinical course, and outcome of fever and neutropenia in children with cancer using the current guidelines and diagnostic resources should be regularly upgraded.

A total of 70 samples from 30 children with marrow/ biopsy evidence of malignancy and clinical features of febrile neutropenia were included. Out of 26 culture positive cases $6(23.2 \%), 12(46.1 \%)$ and $8(30.7 \%)$ bacteria were isolated from blood, urine and wound swab culture respectively.Isais-Agdeppa and Bravo in a retrospective study determined the bacterial blood isolates of pediatric cancer. ${ }^{7}$ A total of 90 patients were included and $7 \%$ of the patients had growth in the blood culture. In this study bloodstream infection is higher $(23.2 \%)$ than the previous study. ${ }^{7}$ It is probably due to higher numberchildren had absolute neutrophil count $($ ANC) $<100$. Patients with neutrophil count of $<100$ cells/cmm are at greater risk than are those with counts of $<500$ cells $/ \mathrm{cmm}{ }^{4}$ Jones et alreported thatblood cultures were positive in $58 \%$ cases of fever episodes with an absolute neutrophil count $<500 / \mathrm{cmm} .{ }^{13}$ Bacterial infection rate increased when an absolute neutrophil count $<500 / \mathrm{cmm}$ were also observed in other studies in different geographical areas. ${ }^{14,15}$

In this study distribution among 26 patients with culture positive cases $10(30.3 \%)$ had ANC count more than 100 cells/cmm and $23(69.7 \%)$ had ANC count less than 100 cells/cmm. So bacterial infectionrate was significantly higher in those cases had ANC count less than 100 cells $/ \mathrm{cmm}$ and these findings were similar with the previous study. Hana et al studied the etiology, clinical course, and outcome of fever and neutropenia in children with cancer. ${ }^{6}$ Infection was proven in $25 \%$ and bacteremia accounted for $41 \%$ of the proven bacterial episodes, with Viridans streptococci 13\%, Pseudomonas spp. 6\% and Escherichia coli 6\%were the most frequently isolated organisms. Mahmud et alobserved total 29 bacteria were cultured in 62 febrile episodes. ${ }^{16}$ Among them 55\%organisms were isolated from blood and $45 \%$ from other sites with $51.7 \%$ and $48.3 \%$ were gram negative and positive bacteria respectively.

In this study Isolation from blood was $23.3 \%$ and from other sites $76.8 \%$ and the isolation rate of gram negative bacteria was higher than the gram positive bacteria. Isolated gram positive bacteria were $100 \%$ sensitive to vancomycin and linezolid whereas gram negative bacteria were most sensitive to meropenem, imipenem and netilmicin in this study.Antibiotic prophylaxis reduces the incidence of fever, but its routine use remains controversial for patients at low risk of neutropenic infection. ${ }^{17,18}$ The most serious form of sepsis originates from the gram-negative group and empiric antibiotic regimens offer good control over this group. ${ }^{19}$ A typical choice would be an anti-pseudomonal beta-lactam and an aminoglycoside, e.g. piperacillin/tazobactam plus amikacin. ${ }^{20}$ Other monotherapy regimens of $3^{\text {rd }}$ or $4^{\text {th }}$ generation cephalosporins with anti- pseudomonal activity, like ceftazidime or cefepime, may also be used provided cognizance, pleading. ${ }^{21}$

Despite improvement in supportive care measures, most febrile, neutropenic patients need close observation and empiric intravenous antibiotic therapy. So, culture and susceptibility test should be performed regularly for proper treatment and management of febrile neutropenic children under chemotherapy.

\section{Ethical consideration}

Prior to commencement of this study, the research protocol was approved by ethical committee of Bangladesh College of Physician and Surgeons, Dhaka. Informed consent was obtained from the legal guardian of the children.

\section{Acknowledgement:}

The authors thankfully acknowledge the Department of Pediatric Haematology and Oncology, BSMMU, Dhaka for providing the sample collection facility.

\section{Conflict of interest}

We do not have any potential conflicts of interest. 


\section{References:}

1. Khan MA, Siddiqui BK, Shamim A, et al. Emergingbacterial resistance patterns in febrile neutropenic patients: experience at a tertiary care hospital in Pakistan. JPMA 2004; 54:357-9.

2. Nijhuis CO, Kamps WA, Daenen SMG, et al. Feasibility of withholding antibiotics in selected febrile neutropenic cancer patients. J Clin Oncol 2005; 23: 7437-7444.

3. Viscoli $\mathrm{C}$ and Castagnola E. Treatment of febrile neutropenia: what is new? Curr Opin Infect Dis 2002; 15:377-82.

4. Hughes WT, Armstrong D, Bodey GP, et al. Guidelines for the use of antimicrobial agents in neutropenic patients with cancer CID 2002;34:730-751.

5. Tezcan G, Kupesiz A, Ozturk F, et al. Episodes of fever and Neutropenia in children with cancer in a tertiary care medical center in Turkey. Pediatr Hematol Oncol 2006;23: 217-229.

6. Hana H, Patricia MF, Katherine MK, Deo Kumar S, Aditya HG. Etiology and clinical course of febrile neutropenia in children with cancer. J Pediatr Hematol Oncol 2009;31(9):623-629.

7. Isais-Agdeppa AT and Bravo L. A five-year retrospective study on the common microbial isolates and sensitivity pattern on blood culture of pediatric cancer patients admitted at the Philippine general hospital for febrile neutropenia. PIDSP J 2005; 9:19-26

8. Vandepitte J, Verhaegen J, Engback K, Rohner P, Piot P, Heuck CC. Basic laboratory procedures in clinical bacteriology. WHO. Second edition 2003.

9. Collee JF, Miles RS, Watt B. Tests for the identification of bacteria. Practical Medical Microbiology. Fourteenth Edition 1996.

10. Bauer AW, Kirby WM, Sherris JC, Turck M. Antibiotic susceptibility testing by a standardized singledisc method. AM J Clin Pathol 1966; 45: 493-6.

11. CLSI. Performance standards for antimicrobial susceptibility testing; Informational supplement, CLSI document, Wayne, PA: Clinical and Laboratory Standards Institute 2010.
12. Cagol AR, de Castro Junior CG, Martins MC, et al. Oral vs. intravenous empirical antimicrobial therapy in febrile neutropenic patients receiving childhood cancer chemotherapy. J Pediatr 2009; 85(6): 57-59.

13. Jones GR, Konsler GK, Rose P, Dunaway RP, Pusek SN. Infection risk factors in febrile, neutropenic children and adolescents. Pediatr Hematol Oncol 1996; 13(3): 217-229.

14. Jennifer $\mathrm{P}$ and Neil S. Antibiotics for the prevention of febrile neutropenia. CurrOpin Hematol 2009; 16(1): 48-52.

15. Cullen M and Baijal S. Prevention of febrile neutropenia: use of prophylactic antibiotics. Br J Cancer 2009; 101:11-14.

16. Mahmud S, Ghafoor T, Badsha S, Gul MS. Bacterial infections in paediatric patients with chemohterapy inducednetropenia. J Pak Med Assoc 2004; 54: 237-243.

17. Saeidpour M, Hamedi AK, Hanachi P.Pattern of bacterial and fungal infections in neutropenic paediatric patients. Iran J Med Sci 2008; 33: 202-208.

18. Santolaya ME, Alvarez AM, Avilés CL, et al. Early hospital discharge followed by outpatient management versus continued hospitalization of children with cancer, fever, and neutropenia at low risk for invasive bacterial infection. J Clin Oncol 2004; 22(18):3784-3789.

19. Stabell N, Nordal E, Wiger K, et al. Febrile neutropenia in children with cancer; a retrospective Norwegian multicentre study. Presentation: 17th European Congress of Clinical Microbiology and Infectious Diseases ICC, Munich, Germany 2007.

20. Kannangara S. Management of febrile neutropaenia. Community Oncol 2006; 3(9): 585-591.

21. Meckler G and Lindemulder S. Fever and neutropenia in pediatric pertaining to the health of children of or relating to pediatrics patients with cancer. Emerg Med Clin North Am 2009; 27: 525-544. 